\title{
Orta Asya Türk Cumhuriyetlerinde Kent Nüfus Büyüklüklerinin Dağılımı: ZiPF Kanunu
}

\author{
City Size Distributions in Central Asian Republics: ZIPF'S Law
}

Utku AKSEKi' ${ }^{1}$, Barış GÖK², Ertuğrul DELIKTAŞ³

\begin{abstract}
ÖZET
$\mathrm{Bu}$ çalışmanın amacı Azerbaycan, Kazakistan, Kırgızistan, Tacikistan ve Özbekistan'ın kent nüfus büyüklüklerinin dağılımlarının Sovyet Birliği ve sonrası dönemde farklılık gösterip göstermediğini Zipf Kanunu çerçevesinde analiz etmektir. Bu amaçla ülkelerin sosyalist dönemde ve sonrasında kent nüfus verileri kullanılarak farklı yılları kapsayan yatay kesit verilerine dayalı Zipf regresyon analizi yapılmıştır. Analiz sonuçlarına göre Azerbaycan ve Özbekistan dışında kalan diğer üç ülkede ekonomik sistemlerin farklılaşması kent nüfus büyüklerinin dağılımında dikkate değer değişikliklere sebep olmamıştır.
\end{abstract}

Anahtar Kelimeler: Kent büyümesi, Zipf kanunu, orta asya ülkeleri.

\section{GíRiş}

Kentlerin nüfus dağılımı açısından Zipf kanunu (Zipf, 1949), iktisattaki ya da genel olarak sosyal bilimlerdeki en dikkat çekici ampirik bulgulardan biridir (Gabaix, 1999b: 739). Zipf kanununa göre bir ülke ya da bölgedeki yerleşim yeri (kentler, kasabalar vb.) nüfus büyüklüklerinin sıralaması ile bu yerleşim yerlerinin nüfusları arasında ters orantılı bir ilişki bulunmaktadır. Bu kanuna göre kentler en yüksek nüfusa sahip olandan en az nüfusa sahip olana doğru 1'den başlayarak sıralanırsa, bu sıralamanın logaritmasının $Y$ ekseninde, ilgili yerleşim yerlerinin nüfus büyüklüklerinin logaritmasının X ekseninde yer aldığı bir grafikte, eğimi -1 olan bir doğru elde edilecektir. Bu tablodan çıkan sonuç, en yüksek nüfuslu ikinci yerleşim yerinin nüfusunun en yüksek nüfuslu birinci yerleşim yerinin nüfusunun $1 / 2$ 'si, üçüncünün nüfusunun birincinin $1 / 3^{\prime}$ ü, dördüncünün nüfusunun birincinin 1/4'ü kadar olduğu ve bu sıralamanın böylece devam edeceği şeklindedir.

Kent nüfus büyüklükleri ile sıralamaları arasında Pareto dağılımına uyan bir ilişki olduğu literatürde ilk kez Auerbach (1913) tarafından belirtilmiştir

\begin{abstract}
The aim of this paper is to analyze whether there is a difference in city size distribution of Azerbaijan, Kazakhstan, Kyrgyzstan, Tajikistan, and Uzbekistan between in the era of socialism and in the post-era of socialism within the framework of the Zipf's law. Cross section data analysis is used for both periods in these countries to estimate Zipf's law. Empirical results show that different economic systems have not caused remarkable changes in the city size distribution of analyzed countries except Azerbaijan and Uzbekistan in the periods of socialism and post-socialism.
\end{abstract}

Keywords: City's growth, Zipf's law, central asian countries.

(loannides\&Overman, 2003; Nitsch, 2005; Soo, 2005). Daha sonra Zipf kanununa adını veren çalışmasında Zipf (1949), şehirlerin nüfus büyüklüğü dağılımının Pareto katsayısının 1'e eşit olduğu Pareto dağılımının özel bir hali olduğunu ileri sürmüştür. Bu çalışmadan sonra literatürde şehirlerin nüfus dağılımını Zipf kanunu çerçevesinde inceleyen birçok çalışma yapılmıştır. Türkiye için yapılan çalışmalardan Marın (2007), çalışmasında 1985, 1990 ve 2000 yıllarına ait nüfus sayımı verilerini kullnamış ve Zipf yasasından uzaklaşıldığını bulmuştur. Deliktaş vd. (2013) ise 1980-2007 dönemi için Zipf Kanunu'nun Türkiye için geçerli olduğunu bulmuştur. Ayrıca doğurganlık hızının, kentin konumunun, göçün, imalat sanayinde uzmanlaşmanın, okullaşma oranıın kentsel nüfus artışı üzerindeki etkilerini ortaya koymuştur.

Diğer ülkeler için Zipf yasasının geçerliliğinin test edildiği çalışmalardan, Brakman vd. (1999) Hollanda için, Giesen ve Suedekum (2009) Almanya için, Soo (2007) Malezya için, loannides ve Overman (2003), Black ve Henderson (2003), Eeckhout (2004) Amerika Birleşik Devletleri için, Eaton ve Eckstein (1997) Fransa ve Japonya için Zipf kanununu önemli ölçüde destekleyen bulgulara ulaşmışlardır. Ancak yasanın

\footnotetext{
1 Sorumlu Yazar, Yrd. Doç. Dr., Ege Üniversitesi, İktisadi ve İdari Bilimler Fakültesi, İktisat Bölümü, utku.akseki@ege.edu.tr

${ }^{2}$ Yrd. Doç. Dr., Ege Üniversitesi, İktisadi ve İdari Bilimler Fakültesi, İktisat Bölümü, baris.gok@ege.edu.tr

${ }^{3}$ Prof. Dr., Ege Üniversitesi, İktisadi ve İdari Bilimler Fakültesi, ìktisat Bölümü, ertugrul.deliktas@ege.edu.tr
} 
varlığını destekleyen çok sayıdaki bulguya rağmen, Zipf kanununun geçerli olmadığı sonucuna varan az sayıdaki çalışma da literatürde yer almaktadır. Bu çalışmalardan Soo (2005) Malezya için Zipf Kanunu'nun 1957 yılı haricinde 1970,1980, 1991 ve 2000 yıllarında geçerli olmadığını bulmuştur. González-Val (2011) 1900-2000 döneminde Zipf Kanunu'nun ABD'de geçerli olmadığı sonucuna ulaşmıştır'.

Yerleşim yerlerinin nüfus dağılımlarının nelere bağlı olarak değiştiği hakkında literatürde temelde iki tip yaklaşım bulunmaktadır. Bunlardan birincisi olan iktisadi açıklamalar, taşıma maliyetlerinin çok hassas biçimde dengelenmesine, negatif ve pozitif dışsallıklara ve verimlilik farklılıklarına dayanırken, ikincisi Gabaix (1999a) tarafından gösterilen rassal süreçlere dayanır. Buna göre yerleşim yerleri (kentler) rassal olarak büyürlerse benzer beklenen büyüme oranılla ve aynı standart sapmayla limit dağılımı Zipf kanununa yakınsayacaktır (Deliktaş, 2008: 3).

Bu çalışmada, iki farklı ekonomik sistem (Sovyet dönemi ve geçiş dönemi) tecrübesine sahip olan Orta Asya ülkelerinden Kırgızistan, Kazakistan, Özbekistan, Tacikistan ve Azerbaycan'ın nüfus dağılımları Zipf kanunu çerçevesinde analiz edilerek kentlerin nüfus dağılımında iki farklı sistemin etkisi olup olmadığı irdelenmeye çalışılmaktadır².

Çalışmanın izleyen bölümlerinde incelenen ülkelerle ilgili olarak genel demografik bilgilere, kentleşmeyi etkileyen bazı temel faktörlere, Zipf Kanunu ile ilgili teorik çerçeveye ve ampirik bulgulara yer verilmiştir. Çalışma sonuç bölümüyle sonlandırıımıştır.

\section{2. ÜLKELERE ILIŞSIN DEMOGRAFIK BiLGILER}

Bu kısımda ülkelerin kent nüfus büyüklükleri dağılımına temel teşkil edecek demografik bilgilere kısaca yer verilmektedir. Bu bağlamda Azerbaycan, Kazakistan, Kırgızistan, Özbekistan ve Tacikistan'ın toplam nüfus büyüklükleri, başlıca önemli kentleri, toplam kent sayıları ve nüfusları ve kentleşme oranları ele alınmaktadır.

Ülkeler tek tek değerlendirildiğinde, Azerbaycan'ın en önemli şehirleri Bakü, Gence, Lenkeran, Mingeçevir, Şeki, Guba, Ali Bayramlıdır (Somuncuoğlu, 2011a: 2). Bakü'nün 1979 yılında 1.021 .969 olan nüfusu $\% 16$ artarak, 2012 yılında 1.184.000'e yükselmiştir. 1999 senesinden yapılan genel nüfus sayımı verilerine göre Azerbaycan'ın nüfusu 7.953.000 kişidir. Bakü ve çevresinde toplam nüfusun yaklaşık \%40'ı yaşamaktadır. 2009 yılında yaklaşık olarak 9 milyon kişiye ulaşan Azerbaycan nüfusunun \%54'ü kentlerde yaşamaktadır (Hüseynova, 2011: 4). 2011 yılında Azerbaycan'da kentleşme oranı $\% 53,6$ 'dır.
Kazakistan Orta Asya Cumhuriyetleri içerisinde yüzölçümü en büyük olan ülkedir. 14 ayrı idari bölge ve 2 büyük şehir olmak üzere 16 idari birime ayrılarak yönetilmektedir (Somuncuoğlu, 2011c: 3). Kazakistan'ın 1999 yılında 14.981.281 olan toplam nüfusu 2009 yılında \% 6,9 artarak 16.009.597 olmuştur. Ülkedeki iki büyükşehirden birisi 1994 yılına kadar Kazakistan'a başkentlik etmiş olan Almatı, diğeri ülkenin yeni başkenti Astana'dır. 1999 yılında 328.300 olan Astana'nın nüfusu neredeyse iki kat artarak 2009 yılında 613.000 olmuştur. 1999 yılında 1.130 .600 olan Almatı nüfusu yaklaşık olarak \% 20 artarak 2009 yılında 1.365.600'e yükselmiştir. Bu iki büyük kentte ülkenin toplam nüfusundaki artış oranından daha yüksek bir oranda artış olduğu görülmektedir. 2012 yılında Almatı'nın nüfusu 1.450.327, Astana'nın nüfusu 742.918 olmuştur. 1999-2012 yılları arasında Astana'nın nüfusu \% 226, Almatı'nın nüfusu \%28 oranında artmıştır. 2009 yılı itibariyle Almatı ülke nüfusunun $\% 8,5^{\prime}$ ini, Astana \%3,8'ini oluşturmaktadır. 2012 yılı için bu oran Almatı için $\% 8,7^{\prime} y e$, Astana için ise \%4,5'e yükselmiştir (The Agency on Statistics of the Republic of Kazakhstan, 2011). 2011 yılında Kazakistan'da kentleşme oranı $\% 53,6^{\prime}$ dir.

Özbekistan'ın en önemli şehirleri Taşkent, Semerkand, Naangan, Buhara, Hive, Hokand, Andican, Karşı, Çızzak, Nevai, Urgenç ve Nukus'tur. 1979 yılında Özbekistan'ın en büyük kenti olan Taşkent'in nüfusu 1.780.002, 1989 yılında 2.072.459, 2005 yılında 2.135 .700 olarak gerçekleşmiştir. 2. büyük kent Semerkand'ın nüfusu 1979 yılında 476.929, 1989 yılında 367.031, 2005 yılında ise 361.200 olarak gerçekleşmiştir. 2011 yılında Özbekistan'da kentleşme oranı $\% 36,2$ 'dir.

Kırgızistan, başkent Bişkek, Çuy ili, Issık-Göl ili, Narın ili, Talas ili, Celalabad ili, Oş ili, Batken ili olmak üzere sekiz idari bölgeye ayrılmıştır (Somuncuoğlu, 2011 b: 2). Bişkek şehrinin nüfusu 1979 yılında 532.931 iken 2010 yılında 833.046'ya yükselmiştir. 1979 yılında 169.000 olan Oş kentinin nüfusu 2010 yılında 234.816 olmuştur. 1979-2010 yılları arasında Bişkek şehrinin nüfusu \%57 artarken Oş kentinin nüfusu \%39 oranında artmıştır. Kırgızistan'da kentleşme oranı \%35,3'tür.

Tacikistan, GBAO, Sogd, Khatlon, Duşanbe, RRP olmak üzere beş ayrı bölgeden oluşmaktadır. Başkenti Duşanbe'nin 1979 senesinde 493.528 olan nüfusu 2010 senesinde $\% 47$ oranında artarak 724.000 olarak gerçekleşmiştir. En önemli ikinci şehri olan Chuçand 1979 senesinde 130.353 iken 2010 senesinde $\% 25$ artarak 162.000 olmuştur. Tacikistan'da kentleşme oranı $\% 26,5$ 'tir. 


\section{3. Ülkeler İtibariyle Kent Nüfus Büyük- lüklerinin Dağılımını Etkileyen Faktörler}

Kentlerin nüfus dağılımını etkileyen çeşitli faktörler bulunmaktadır. Kentlerin sahip oldukları sosyokültürel yapı ve sosyo-ekonomik yapı, iç ve dış göç oranı, coğrafi durum ve farklı ekonomik ve politik sistemler altında olma gibi faktörler kent nüfus büyüklüklerinin dağılımını etkilemektedir. Kentlerin hızlı ya da yavaş büyümesi bu faktörlere bağlı olarak değişebilmektedir (Deliktaş, 2008:4).

Bu bağlamda, Azerbaycan, Kazakistan, Kırgızistan, Tacikistan ve Özbekistan'da sosyalist dönemde ve sonrası dönemde kentlerin nüfus büyüklüklerinin dağılımında iki farklı sistem farklı sonuçlar doğurmuş olabilir. Sosyalist dönemde kentsel nüfus artışının temel dinamikleri doğal nedenlerden çok mekanik nedenlerdir. Diğer bir ifadeyle, bu ülkelerde 19. Yüzyılın ikinci yarısından 1970'li yılların başına kadar nüfusun doğal olarak değil mekanik olarak değiştiği gözlenmektedir (Asylbekov, 2007:156).

Sovyetler Birliği döneminde Rusya'da yapılan tarım reformları, göç, kolektifleştirme gibi nedenlerle özellikle kentlerdeki nüfus artmıştır. Sovyetler Birliği'nin çözülmesinden sonra bu ülkelerde ikamet eden etnik azınlığın anavatanlarına geri dönmeye başlamaları sebebiyle kentsel nüfus oranı kabaca ilk 10 sene azalmıştır (bkz. Şekil 1).

Şekil 1'de 1950-2015 yılları arasında Kazakistan, Özbekistan, Kırgızistan, Tacikistan, Azerbaycan ve dünyada kentleşme oranındaki değişim görülmektedir. Dünyada kentleşme oranının trend olarak artmaktadır. 2010 yılından sonra yalnızca Azerbaycan ve Kazakistan'ın kentleşme oranı dünyadaki ortalama kentleşme oranı seviyesindedir (WHO, 2013). Orta Asya Cumhuriyetlerinde petrol ve petrol benzeri ürünler kentleşme oranını etkileyen önemli ekonomik faktörler arasında gösterilmektedir. Nitekim Orta Asya'daki ülkeler arasında petrol ve petrol benzeri ürünler ihraç eden ülkelerin kentleşme oranlarının yüksek olduğu Birleşmiş Milletlerin 2011 senesinde çıkardığı ESCAP Raporu'nda belirtilmiştir. Buna göre petrol zengini Orta Asya ülkelerinde kentleşme oranlarının yüksek olduğuna, aksine petrol ya da petrol benzeri ürünleri üretemeyen Kırgızistan ve Tacikistan gibi ülkelerde kentleşme oranlarının düşük olduğuna dikkat çekilmiştir (United Nations ESCAP, 2011: 45). Örneğin Azerbaycan'da 2001 yılında kentsel nüfus oranındaki artış trendinin en önemli nedeni petrol sanayinde oluşan istihdam olanaklarıdır (Somuncuoğlu, 2011a:4).

Şekil 1'de 1990 senesinden önce bu cumhuriyetlerde trend olarak kent nüfuslarında artış olduğu görülmektedir. Diğer bir ifadeyle sosyalist dönemde ülkelerin kentleşme oranları artmıştır. Orta Asya Cumhuriyetlerinin bağımsızlıklarını elde ettikleri 1990'ların başından itibaren kentleşme oranı bu ülkelerde ya duraklamış ya da azalma eğilimi göstermiştir.

Bu ülkeler bağımsızlıklarını elde ettikten sonra piyasa ekonomisine uyum sağlama amacıyla farklı oranlarda 'reformlar' yapmışlardır. Kırgızistan'ın bağımsızlık sonrasında piyasa ekonomisine geçiş için yaptığı reformlar değerlendirildiğinde diğer Orta Asya ülkelerine göre daha çok reform yanlısı olduğu reform endekslerinde görülmektedir. Fiyat serbestleşmesinde, geniş çaplı ve küçük çaplı özelleştirmede, ticaret ve döviz kuru sistemlerinde, rekabet politikasında Kırgızistan, reform endekslerine göre birinci sırada yer almaktadır. Özbekistan ise bu ülkeler arasında en az reformist ülke olarak göze çarpmaktadır (EBRD, 2012).

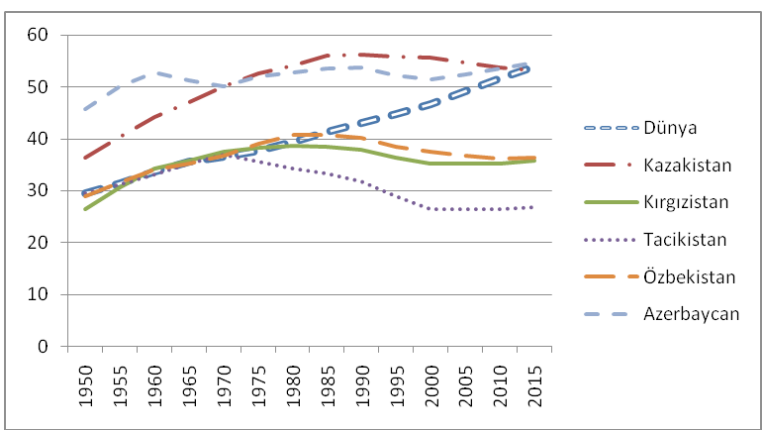

Şekil 1: Dünyada ve Orta Asya Cumhuriyetlerinde Kentsel Nüfus Oranı (1950-2015).

\section{(Kaynak: World Health Organization.)}

Kentlerin nüfus dağılımlarını etkileyen faktörlerden bir diğeri göçtür. Sovyetler Birliği döneminde Rusya Federasyonu, Ukrayna gibi Sovyetler Birliği'nin batısında yer alan ülkelerden Orta Asya ülkelerine doğru var olan göç hareketi piyasa ekonomisinin uygulanması ile birlikte yön değiştirmiştir. Örneğin, Kazakistan'ın piyasa ekonomisine geçişi ile birlikte ülkedeki vasıflı işgücü ülke dışına göçmüştür (Tolesh, 2012:5-6). "Özellikle entelektüel ve yaratıcı potansiyelin kitlesel göçü" Kazakistan ekonomisini yıpratmıştır (Asylbekov, 2007:156-158). Kazakistan için gözlenen bu durum diğer Orta Asya cumhuriyetlerinde de gözlenmektedir ${ }^{3}$.

İncelenen ülkelerde sosyalist dönemde ve sonrası dönemde kentleşme oranı içsel ve dışsal faktörler olarak sınıflandırılabilecek birçok faktörden etkilenmektedir. Sosyalist dönemde göze çarpan ve kentlerin nüfusunu etkileyen faktörlerin başında merkezi yapının uyguladığı politikalar sonucunda vasıflı işgücünün kentlere göç etmesi gelmektedir. Sosyalist dönem sonrasında ise piyasa ekonomisinin uygulan- 
maya başlanması ile birlikte emek faktörünün işsizlik sorunuyla baş etmek için göç ettiği ve özellikle etnik azınlıkların sosyo-ekonomik ve sosyo-kültürel sebeplerle anavatanlarına geriye döndüğü görülmüştür.

\section{ZIPF KANUNU'NUN TEORIK ÇERÇEVESI}

Zipf kanunu ekonomide ve sosyal bilimlerde dikkat çekici kanunlardan birisidir. 'Sıra-büyüklük kuralı' olarak da bilinen Zipf kanunu belli bir zaman dahilinde veya zaman anında kentlerin nüfus büyüklükleri ile sıralamaları arasında ters yönlü bir ilişki olduğunu ifade etmektedir.

Zipf kanunu, şehirlerin nüfus dağılımlarının Pareto dağılımına sahip olabileceğini dolayısıyla bunun $R_{t}=\alpha_{t} N_{i t}{ }^{-\beta}$ üstel fonksiyon biçiminde gösterilebileceğini ifade etmektedir (Zipf, 1949). Fonksiyonda her iki tarafın logaritması alındığında denklem aşağıdaki biçime dönüşür.

$$
\ln \left(R_{t}\right)=\ln \alpha_{t}-\beta_{t} \ln N_{i t}+u_{i t}
$$

Yukarıdaki denklem (1)'de $\alpha_{t} \alpha_{t}$, en büyük kentin beklenen nüfusunu; $R_{t}$, t döneminde i'inci kentin sıralamasını; $N_{i t}$, i'inci kentin nüfusunu ve $u_{i t}$, hata terimini temsil etmektedir. Zipf kanununa göre örneklemdeki kentlerin nüfus dağılımı kanunun öngördüğü şekilde bir dağılım gösteriyorsa $\beta$ katsayısı 1'e eşit ya da çok yakın bir değer alacaktır.

Literatürde bir kısım çalışmalar (1) no'lu denklemin sapmalı sonuç verdiğini belirtmiştir. Bu sapma ilgili denklemin Gabaix ve Ibragimov (2008) tarafından modifiye edilerek sapmasız standart hatalara erişilmesi ile giderilmiştir.

$$
\ln \left(R_{t}-1 / 2\right)=\ln \alpha_{t}-\beta_{t} \ln N_{i t}+u_{i t}
$$

Genelde literatürde yer alan çalışmalarda Pareto katsayısı 0,49 ile 1,96 arasında değişmektedir. Pareto katsayısı bir kentsel sistemde nüfusun kentler arasında ne kadar düzenli dağıldığını ortaya koymaktadır. Bu katsayının 1'in üstünde olması durumunda nüfusun küçük kentlerde nispeten yoğunlaştığı ve 1 'in altında olması durumunda ise nüfusun daha çok büyük kentlerde yoğunlaştığı söylenebilir. Yine farklı zaman dönemleri için Pareto katsayısındaki düşme büyük nüfuslu kentlerin az nüfuslu yerlere göre daha hızlı büyüdüğünü göstermektedir. Pareto katsayısı, yeni kentlerin kent sistemine girmesiyle de düşebilir. Ancak kent sayısı aynı kalırken Pareto katsayısı değişir- se bu değişme başka faktörlerle açıklanabilir (Marın, 2007: 35).

\section{AMPIRIK BULGULAR}

Bu çalışmada beş ülkeye (Kazakistan, Kırgızistan, Özbekistan, Tacikistan, Azerbaycan) ait nüfus verileri kullanılmıştır. Çalışmanın amacı iki farklı ekonomik sistemi uygulamış olan Orta Asya ülkelerinde Zipf yasasının geçerliliğini araştırmak olduğu için, bu ülkelerin 1991'den önce ve sonra en az bir tane nüfus sayımı verisinin bulunması, karşılaştırma için yeterli olabilecektir. Sovyetler Birliği döneminde bu ülkeler için 1979 ve 1989 yıllarında genel nüfus sayımı yapılmıştır. Ancak sözkonusu ülkeler piyasa sistemine geçtikten sonra farklı yıllarda genel nüfus sayımları yaptıkları için 1991'den sonra elde edilen nüfus verisi bazı ülkeler için farklı yıllara ait olabilmektedir. Çalışmada incelenen temel soru ekonomik sistem değişikliğinin Zipf yasasının geçerliliği üzerindeki etkisinin karşılaştırılması olduğundan, 1991 sonrası gerçekleşen bu farklılık inmal edilebilir düzeydedir.

Çalışmada Kazakistan'ın 1979, 1989 ve 2012; Özbekistan'ın 1979, 1989, 2005; Kırgızistan'ın 1979, 1989 ve 2012; Azerbaycan'ın 1979, 1989, 2012; Tacikistan'ın 1979, 1989, 2010 yıllarına ait olan nüfus verileri kullanılmıştır. Özbekistan ve Tacikistan için 2012 yılına ait nüfus sayımları bulunmamaktadır. Dolayısıyla erişilebilen en son sayımına ilişkin veriler dikkate alınmıştır. Veriler City Population'dan edinilmiştir (CP, 2013).

Gabaix ve Ibragimov (2008) tarafından modifiye edilen (2) numaralı denklem, çalışmada kullanılan modeldir. Çalışmada en küçük kareler yöntemi kullanılarak yatay kesit verilere dayalı analiz yapılmıştır. Analiz sonuçları ülkeler itibariyle aşağıdaki gibidir:

\subsection{Azerbaycan}

Azerbaycan için sosyalist dönem ve sonrası döneme ait kent nüfus verileri kullanılarak yapılan tahmin sonuçları Tablo 1'de yer almaktadır. 1979,1989 ve 2012 yıllarındaki beta katsayıları değerlendirildiğinde kent nüfus büyüklüklerindeki dağılımın 2012 yılında büyük kentler lehine bozulduğu belirlenmiştir. Diğer bir ifadeyle Azerbaycan'da sosyalist dönemde nüfusun kentlere dağılımının paralel bir büyüme sergilediği ancak sosyalist sonrası dönemde Pareto katsayısının 1 'in altına indiği, diğer bir ifadeyle nüfus dağılımında bozulma olduğu görülmektedir. 
Tablo 1: Azerbaycan için Regresyon Sonuçları

\begin{tabular}{|c|c|c|c|c|c|c|c|}
\hline \multicolumn{8}{|c|}{ Metot: En Küçük Kareler } \\
\hline \multicolumn{8}{|c|}{$\begin{array}{l}\text { Bağımlı Değişken }: \ln \left(R_{t}-1 / 2\right) \\
\text { Bağımsız Değişken }: \ln N_{i t}\end{array}$} \\
\hline YII & Sabit & t-ist. & $\ln N_{\mathrm{tt}}$ & t-ist. & $\mathrm{R}^{2}$ & F-ist. & $\begin{array}{c}\mathrm{N} \\
\text { (Kent } \\
\text { SayısI) }\end{array}$ \\
\hline 1979 & 13,53 & 41,31 & $-1,05$ & $-32,58$ & 0,96 & 1061,56 & 49 \\
\hline 1989 & 14,18 & 37,57 & $-1,09$ & $-29,99$ & 0,95 & 899,9 & 49 \\
\hline 2012 & 12,95 & 20,75 & $-0,95$ & $-16,16$ & 0,85 & 261,25 & 49 \\
\hline
\end{tabular}

\subsection{Kazakistan}

Kazakistan'da kent nüfus büyüklükleri dağılımının her iki dönem altında önemli bir değişiklik göstermediği veya Pareto katsayılarının önemli bir değişikliğe uğramadığı görülmektedir. Bu katsayıların 1'e yakın olarak tahmin edilmesi Kazakistan'da daha stabil bir nüfus yapısının olduğuna işaret etmektedir.

Tablo 2: Kazakistan için Regresyon Sonuçları

\begin{tabular}{|c|c|c|c|c|c|c|c|}
\hline \multicolumn{8}{|c|}{ Metot: En Küçük Kareler } \\
\hline \multicolumn{8}{|c|}{$\begin{array}{l}\text { Bağımlı Değişken }: \ln \left(R_{t}-1 / 2\right) \\
\text { Bağımsız Değişken }: \ln N_{i t}\end{array}$} \\
\hline YII & Sabit & t-ist. & $\ln N_{i t}$ & t-ist. & $\mathrm{R}^{2}$ & F-ist. & $\begin{array}{c}\mathrm{N} \\
\text { (Kent } \\
\text { Sayısı) }\end{array}$ \\
\hline 1979 & 13,24 & 41,87 & $-0,92$ & $-31,55$ & 0,93 & 995,12 & 74 \\
\hline 1989 & 13,57 & 42,92 & $-0,94$ & $-32,59$ & 0,94 & 1062,19 & 74 \\
\hline 2012 & 13,69 & 58,004 & $-0,95$ & $-44,17$ & 0,96 & 1951,95 & 74 \\
\hline
\end{tabular}

\subsection{Kırgızistan}

Kırgızistan'ın kent nüfus dağılımına ilişkin tahmin sonuçları Tablo 3'te verilmektedir. Kent nüfus büyüklükleri dağılımının özellikle geçiş döneminde bozulmaya başladığı, diğer bir ifadeyle Pareto katsayısının giderek 1'den uzaklaştığı görülmektedir.

Tablo 3: Kırgızistan için Regresyon Sonuçları

\begin{tabular}{|c|c|c|c|c|c|c|c|}
\hline \multicolumn{8}{|c|}{ Metot: En Küçük Kareler } \\
\hline \multicolumn{8}{|c|}{$\begin{array}{l}\text { Bağımlı Değişken }: \ln \left(R_{t}-1 / 2\right) \\
\text { Bağımsız Değişken }: \ln N_{i t}\end{array}$} \\
\hline Yil & Sabit & t-ist. & $\ln N_{i t}$ & t-ist. & $\mathrm{R}^{2}$ & F-ist. & $\begin{array}{c}\mathrm{N} \\
\text { (Kent } \\
\text { Sayısı) }\end{array}$ \\
\hline 1979 & 11,79 & 41,84 & $-0,94$ & $-33,01$ & 0,97 & 1089,67 & 34 \\
\hline
\end{tabular}

\begin{tabular}{|c|c|c|c|c|c|c|c|}
\hline 1989 & 12,01 & 48,27 & $-0,95$ & $-38,26$ & 0,98 & 1463,57 & 34 \\
\hline 2010 & 11,46 & 57,78 & $-0,90$ & $-45,24$ & 0,98 & 2046,74 & 34 \\
\hline
\end{tabular}

\section{4. Özbekistan}

Özbekistan için yapılan regresyon analizi sonuçları Tablo 4'te görülmektedir. Analiz sonuçlarına göre 1979'da beta katsayısı, 1'den küçük iken 1989 ve 2005 'te ise beta katsayısı 1 'in üzerine çıkmıştır. $\mathrm{Bu}$ durum 2005'te Özbekistan'da küçük kentlerin nüfus yoğunluğunun sosyalist döneme göre $(1979,1989)$ nispeten arttığını ifade etmektedir.

Tablo 4: Özbekistan için Regresyon Sonuçları

\begin{tabular}{|c|c|c|c|c|c|c|c|}
\hline \multicolumn{8}{|c|}{ Metot: En Küçük Kareler } \\
\hline \multicolumn{8}{|c|}{$\begin{array}{l}\text { Bağımlı Değişken }: \ln \left(R_{t}\right. \\
\text { Bağımsız Değişken }: \ln N N_{i t}\end{array}$} \\
\hline Yıl & Sabit & t-ist. & $\ln N_{i t}$ & t-ist. & $\mathrm{R}^{2}$ & F-ist. & $\begin{array}{c}\mathrm{N} \\
\text { (Kent } \\
\text { Sayısı) }\end{array}$ \\
\hline 1979 & 13,29 & 83,55 & $-0,96$ & $-63,04$ & 0,98 & 3973,78 & 74 \\
\hline 1989 & 14,39 & 85,36 & $-1,04$ & $-65,38$ & 0,98 & 4274,99 & 82 \\
\hline 2005 & 15,08 & 85,14 & $-1,08$ & $-66,25$ & 0,98 & 4388,66 & 80 \\
\hline
\end{tabular}

\subsection{Tacikistan}

Tacikistan'da kent nüfus büyüklükleri dağılımına ilişkin regresyon analizinin sonuçları Tablo 5'te görülmektedir. 1979'da beta katsayısı, 1989 ve 2005'teki beta katsayısına göre 1'in üstünde ancak 1'e daha yakın çıkmıştır. Bu durum Özbekistan'da kent nüfus büyüklüklerinin dağılımının paralel bir seyir izlemediğini göstermektedir. Ancak beta katsayısının giderek büyümesi Zipf kanunundan uzaklaşıldığının ve nüfus dağılımının küçük kentler lehine değiştiğinin göstergesi olarak kabul edilebilir.

Tablo 5: Tacikistan için Regresyon Sonuçları

\begin{tabular}{|c|c|c|c|c|c|c|c|}
\hline \multicolumn{8}{|c|}{ Metot: En Küçük Kareler } \\
\hline \multicolumn{8}{|c|}{$\begin{array}{l}\text { Bağımlı Değişken }: \ln \left(R_{t}-1 / 2\right) \\
\text { Bağımsız Değişken }: \ln N_{i t}\end{array}$} \\
\hline Yıl & Sabit & t-ist. & $\ln N_{i t}$ & t-ist. & $\mathrm{R}^{2}$ & F-ist. & $\begin{array}{c}\mathrm{N} \\
\text { (Kent } \\
\text { Sayısı) }\end{array}$ \\
\hline 1979 & 13,03 & 47,04 & $-1,07$ & $-37,55$ & 0,97 & 1409,68 & 39 \\
\hline 1989 & 13,40 & 49,74 & $-1,08$ & $-39,89$ & 0,98 & 1590,67 & 40 \\
\hline 2010 & 13,92 & 60,45 & $-1,11$ & $-48,91$ & 0,98 & 2391,82 & 40 \\
\hline
\end{tabular}




\section{SONUÇ}

Bu çalışmada Orta Asya ülkelerinden Azerbaycan, Kazakistan, Kırgızistan, Özbekistan ve Tacikistan'da kent nüfus büyüklüklerinin dağılımı sosyalist dönem ve sonrası dönem için Zipf Kanunu çerçevesinde incelenmiştir. Bu kapsamda ülkelerin kent nüfus büyüklükleri dağılımına ilişkin regresyon analizi yapılarak nüfus büyüklüklerinin dağılımının nasıl olduğu tespit edilmeye çalışılmıştır.

Analiz sonuçlarına göre Azerbaycan ve Özbekistan dışında kalan diğer üç ülkede (Kazakistan, Tacikistan ve Kırgızistan) ekonomik sistemlerin farklılaşması kent nüfus büyüklerinin dağılımında dikkate değer bir değişikliğe sebep olmadığı sonucuna ulaşılmıştır. Öte yandan Azerbaycan'da ve Özbekistan'daki kentsel nüfus dağılımı Zipf yasasından farklı yönlerde sapma göstermiştir. Buna göre Azerbaycan'da kentsel nüfus dağılımının piyasa ekonomisi döneminde büyük kentler lehine, Özbekistan'da ise aynı dönemde kentsel nüfus dağılımının küçük kentler lehine değiştiği söylenebilir.

Ampirik bulgularda Azerbaycan'ın piyasa ekonomisi döneminde kentlerin nüfus dağılımının daha dengesiz çıkmasının çeşitli nedenleri olabilir. Azerbaycan'da piyasa ekonomisi döneminde petrol sanayinde sağlanan gelişmelerin etkisiyle Bakü ve çevresinde nüfusun yoğunlaştığı görülmektedir. 2001 yılından bu yana petrol sanayinde çalışmak üzere gelen nitelikli işgücünün Bakü ve çevresine göç etmesi sonucunda kentsel nüfus oranı artış trendine girmiştir. Sonuç olarak piyasa ekonomisi döneminde büyük kentler lehine kentsel nüfus dağılımının değişmesinin nedeni petrol sanayinde oluşan istihdam olanakları olabilir.

Ampirik bulgularda Özbekistan'da piyasa ekonomisi döneminde kentsel nüfus dağılımının küçük kentler lehine bozulmasının çeşitli nedenleri olabilir. Sosyalist dönem sonrasında Özbekistan'da kentteki yerleşiklerin ekonomik reformlara adapte olamaması nedeniyle kentlerden köylere göç olmuştur (Aman, 1999: 25). Bu göç hareketi kentsel nüfus dağılımının büyük kentler aleyhine değişmesine neden olmuş olabilir.

Sonuç olarak, ekonomik sistemlerin farklılaşmasının incelenen ülkelerde kentlerin nüfus dağılımında önemli bir değiş̧ikliğe sebep olmadığı gözlemlenmiştir. Azerbaycan ve Özbekistan dışındaki ülkelerde sosyalist dönemde ve sonrasında nüfusun kentlere olan dağılımında belirgin bir farklılık görülmemiştir. Azerbaycan ve Özbekistan'da ise ekonomik sistemdeki değişikliğin kentsel nüfus dağılımını aksi yönde ve belirgin biçimde değiştirdiği görülmüştür. 


\section{SON NOTLAR}

Bu çalıșmanın ilk versiyonu 26-28 Haziran 2013 tarihleri arasında Kırgızistan- Türkiye Manas Üniversitesi'nde düzenlenen Uluslararası İktisat, Finans ve Bankacılık Kongresi'nde sunulmuştur.

${ }^{1}$ Zipf yasası hakkında ayrıntılı literatür taraması için bkz. Nitsch, 2005.

${ }^{2}$ Orta Asya Türk Cumhuriyetlerinden olduğu halde
Türkmenistan, nüfus verilerinin eksikliği nedeniyle bu çalışmada analiz edilememiştir.

${ }^{3}$ Diğer Orta Asya ülkeleri hakkında konuyla ilgili bilgi için bkz. Abdullayev (2001), T. C. Bişkek Büyükelçiliği Ticaret Müşavirliği (2008), Somuncuoğlu (2011a) The State Statistical Committee of the Republic of Azerbaijan (2013).

\section{KAYNAKLAR}

Abdullayev, Y. (2001) “Özbekistan'da Ruslar-Şehir Alt-Etnik Grubu: Bir Sosyokültürel Analiz" Avrasya Dosyasi, 7(3):137-151.

Aman, A. (1999) "Population Migration in Uzbekistan" https://src.auca.kg/pdf/POPULATION_MIGRATION_IN_UZBEKISTAN.pdf, (10 Mayıs 2013).

Asylbekov, M. (2007) "Kazakistan'in XX.Yüzylldaki Demografik Gelişimi” Kazakistan Tarihi: Makaleler, Ankara, Türk Tarih Kurumu.

Auerbach, F. (1913) "Das Gesetz Der Bevdlkerungskonzentration" Petermanns Geographische Mitteilungen, 59:74-76.

Henderson, J.V. (2003) "Urban Evolution in the USA" Journal of Economic Geography, 3:343-372.

Brakman, S., Garretsen, H., Marrewijk, C.V. ve Berg, M.V. (1999) "The Return of Zipf: Towards A Further Understanding of The Rank-Size Distribution" Journal of Regional Science, 39(1):183-213.

City Population (2013) "Population Statistics for Singel Countries" http://www.citypopulation.de/mapindex. html, (3 Haziran 2013).

Deliktaş, E. (2008) “Türkiye'de Kentlerin Büyümesi ve Ziph Kanunu” Dokuz Eylül Üniversitesi 2. Ulusal İktisat Kongresi, 20-22 Şubat, İzmir.

Deliktaş, E., Önder, A.Ö. ve Karadağ, M. (2013) "The Size Distribution of Cities and Determinants of City Growth in Turkey" European Planning Studies, 21(2):251-263.

Eaton, J. ve Eckstein, Z. (1997) "Cities and Growth: Theory and Evidence From France and Japan" Regional and Urban Economics, 27(4-5):444-474.

European Bank for Reconstruction and Development (2012) CountryAssesments.http://www.ebrd.com/pages/ research/analysis/forecasts.shtml (13 Mayss 2013).

Eeckhout, J. (2004) "Gibrat's Law for All Cities" The American Economic Review, 94(5):1429-1451.
Gabaix, X. (1999a) "Zipf's Law and the Growth of Cities" The American Economic Review, 89(2):129-132.

Gabaix, X. (1999b) “Zipf's Law for Cities: An Explanation" The Quarterly Journal of Economics, 114(3):739767.

Gabaix, X. ve Ibragimov, R. (2008) "Rank-1/2: A Simple Way to Improve The OLS Estimation of Tail Exponents" National Bureau of Economic Research Technical Working Paper, No:342.

Giesen, K. ve Suedekum, J. (2009) "Zipf's Law for Cities in the Regions and the Country" IZA Discussion Paper Series, No:3928.

González Val, R. (2011) “Deviations from Zipf’s Law for American Cities: An Empirical Examination" Urban Studies, 48(5):1017-1035.

Hüseynova, A. (2011) “Sosyal Güvenlik-Azerbaycan'ın Nüfus Yapısı Bakü:Azerbaycan Devlet İktisat Üniversitesi Türk Dünyası Uluslararası Ekonomik İlişkiler http:// www.belgeler.com/blg/2cau/azerbaycanin-nufus-yapisiayten-huseynli, (13 Mayıs 2013).

Ioannides, Y.M., Overman, H.G. (2003) “Zipf's Law For Cities: An Empirical Examination” Regional Science and Urban Economics, 33:127-137.

Marin, M.C. (2007) “1985 Sonrası Türkiye'deki Kentsel Sistemin Dönüşümü: Zipf Yasasının Bir Testi” Gazi Üniversitesi Mühendislik Fakültesi Dergisi, 22(1):33-38.

Nitsch, V. (2005) "Zipf Zipped" Journal of Urban Economics, 57:86-100.

Oğan, S. (2001) "Demografinin Gölgesi Altında Rusya Kazakistan İlişkileri” Avrasya Dosyası, 7(4):127-161.

Somuncuoğlu, T. (2011a) "Azerbaycan Ülke Raporu” T.C. Başbakanlık Dış Ticaret Müsteşarlığı-İhracatı Geliştirme Etüd Merkezi, Ankara.

Somuncuoğlu, T. (2011b) "Kırgızistan Ülke Raporu" Başbakanlık Dış Ticaret Müsteşarlığı İhracatı Geliştirme Etüd Merkezi. Ankara. 
Somuncuoğlu, T. (2011c) "Kazakistan Ülke Raporu 2011” T.C. Başbakanlık Dış Ticaret Müsteşarlığ1-İhracatı Geliştirme Etüd Merkezi, Ankara.

Soo, K.T. (2005) "Zipf's Law for Cities: A CrossCountry Investigation" Regional Science and Urban Economics, 35:239-263.

Soo, K.T. (2007) “Zipf's Law and Urban Growth in Malaysia” Urban Studies, 44 (1):1-14.

T.C. Bişkek Büyükelçiliği Ticaret Müşavirliği (2008) “Kırgızistan'ın Genel Ekonomik Durumu ve Türkiye ile Ekonomik Ticari İlişkileri” http://www.counsellors.gov. tr/upload/KIR/Rapor2007-3.pdf, (12 Nisan 2013).

The Agency on Statistics of The Republic of Kazakhstan (2011) "Results of the 2009 National Population Cencus of The Republic of Kazakhstan" http://www. eng.stat.kz/publishing/DocLib/2011/AO\%20на\%20 английском.pdf, (4 Mayıs 2013).
Tolesh, A.F.(2012) “The Population History of Kazakhstan” http://epc2012.princeton.edu/papers/120586, (12 Mart 2013).

United Nations Escap (2011) “The States of Asian Cities 2010/11” http://www.unhabitat.org/pmss/listItemDetails.aspx?publicationID=3078 (24 Nisan 2013).

World Health Organization (2013) "Countries Statistics” http://www.who.int/countries/en/, (11 Haziran 2013).

Zipf, G. (1949) Human Behavior and the Principle of Last Effort, Cambridge, MA Addison-Wesle. 


\section{EKLER}

Ek 1: Incelenen Ülkelerin $\ln ($ sıra) - In(nüfus) Grafikleri (Yazarların kendi hesaplamaları)
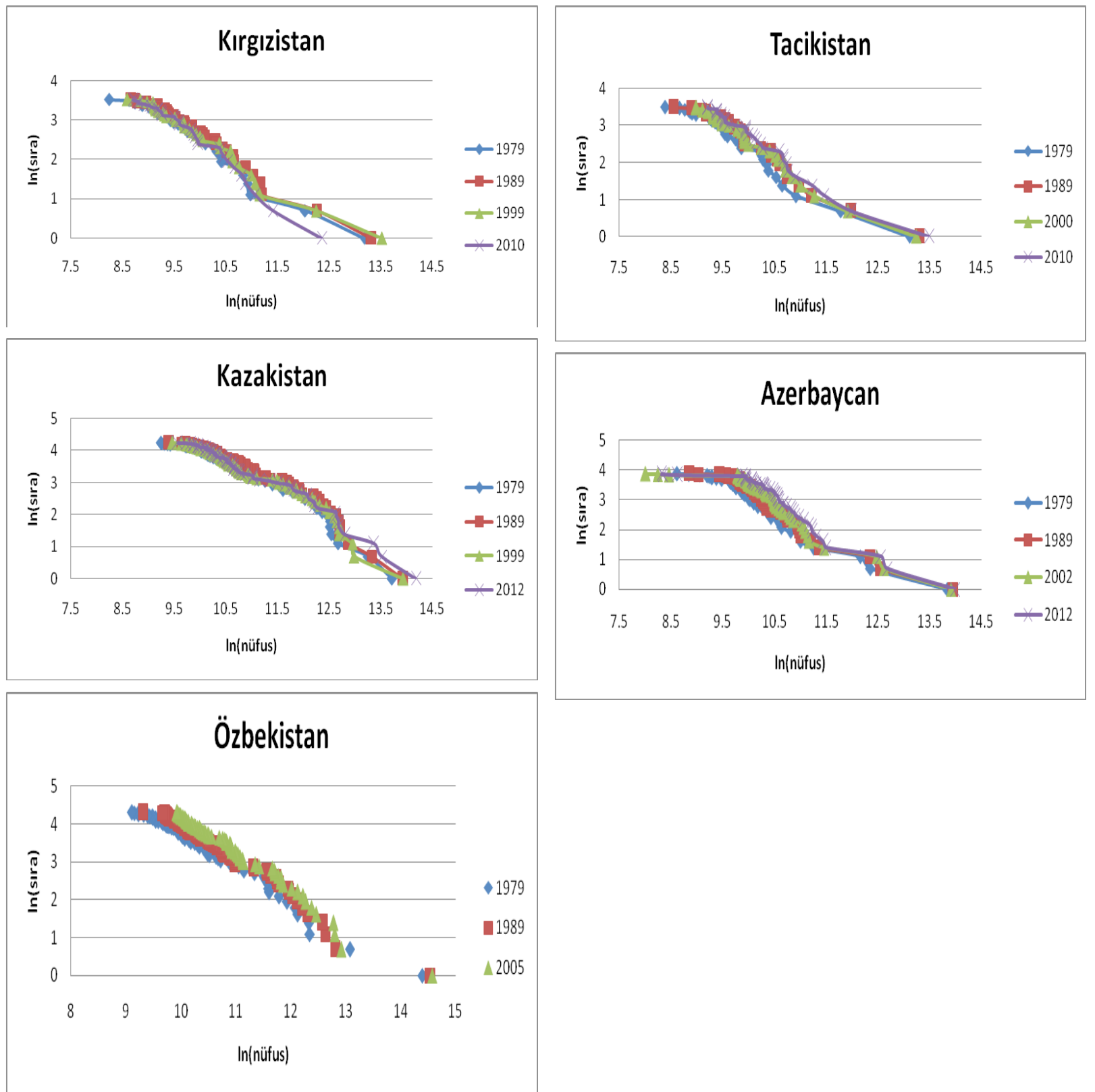
